\title{
PELATIHAN PENGGUNAAN KALIMAT EFEKTIF DALAM KARYA TULIS ILMIAH BAGI GURU UPT SMPN 10 GRESIK
}

\author{
Ira Eko Retnosari ${ }^{1}$, Rahayu Pujiastuti ${ }^{2}$, M. Shoim ${ }^{3}$, Sunu Catur Budiyono ${ }^{4}$ \\ ${ }^{1}$ Program Studi Pendidikan Bahasa Indonesia, Fakultas Ilmu Sosial dan Humaniora, \\ Universitas PGRI Adi Buana Surabaya \\ Email: ira@unipasby.ac.id
}

\begin{abstract}
Informasi Artikel Abstrak
Kata kunci:

kalimat efektif, karya

tulis ilmiah, guru SMP

Diterima: 14-02-2021

Disetujui: 11-06-2021

Dipubikasikan: 16-07-

2021

Dalam penulisan karya tulis ilmiah, diperlukan kalimat efektif. Kalimat efektif adalah kalimat yang dapat mengungkapkan gagasan pemakainya secara tepat dan dapat dipahami secara tepat pula. Bahan kajian yang baik tidak akan dipahami pembaca secara baik apabila penulisnya tidak mampu menjelaskan ide-idenya dengan kalimat efektif. Fenomena yang terjadi saat ini adalah beberapa guru belum menggunakan kalimat efektif dalam menulis karya tulis ilmiah. Berdasarkan fenomena tersebut, perlu dilakukan pelatihan menulis kalimat efektif bagi guru, khususnya penyusunan karya tulis ilmiah (PTK) dalam menulis kalimat efektif pada PTK dalam bentuk Program Pengabdian kepada Masyarakat (PPM). Kegiatan PPM ini telah dilaksanakan oleh Tim Prodi PBI UNIPA Surabaya dan berjalan dengan baik secara virtual. Hal tersebut dapat buktikan dengan berdasarkan hasil tes akhir peserta, kemampuan menulis kalimat efektif guru dengan kriteria kesepadanan struktur sebesar $70 \%$, kecermatan 65\%, kehematan sebesar 80\%, keparalelan $70 \%$, dan kelogisan sebesar 75\%. Dengan demikian, dapat dikatakan bahwa hampir semua peserta dapat menulis kalimat efektif dalam penyusunan PTK sesuai dengan kaidah bahasa Indonesia.
\end{abstract}

\section{Keywords:}

effective sentences, scientific papers, junior high school teachers

\section{Abstract}

In writing scientific papers, effective sentences are needed. Effective sentences are sentences that can express the ideas of the wearer precisely and can be understood precisely too. Good study material will not be well understood by readers if the writer is unable to explain his ideas in the right sentence. The current phenomenon is that some teachers have not used effective sentences in writing scientific papers. Based on this phenomenon, it is necessary to carry out training in writing effective sentences for teachers, especially the preparation of scientific writing (PTK) in writing effective sentences in the CAR in the form of Community Service Program (PPM). This PPM activity has been carried out by the PBI UNIPA Surabaya Study Program Team and is running well virtually. This can be proven by the results of the participants' final tests, the teacher's ability to write effective sentences with the structural equivalence criteria of $70 \%$, accuracy of $65 \%$, savings of $80 \%$, parallelity of $70 \%$, and logic of $75 \%$. Thus, it can be said that almost all participants 
can write effective sentences in the preparation of PTK according to Indonesian principles.

\section{PENDAHULUAN}

Penggunaan kalimat efektif memunyai peranan sangat penting dalam dunia pendidikan, khususnya guru. Dengan menguasai kalimat efektif, guru akan mampu berkomunikasi dengan baik. kalimat dikatakan efektif bila mencapai sasarannya dengan baik sebagai alat berkomunikasi. Ada dua pihak yang terlibat, yaitu yang menyampaikan dan yang menerima, di luar itu, ada yang disampaikan berupa gagasan, pesan, pemberitahuan, dan sebagainya.

Hs (2012) menjelaskan bahwa kalimat efektif adalah kalimat yang singkat, padat, jelas, lengkap, dan dapat menyampaikan informasi secara tepat kepada pembaca atau pendengar. Dengan demikian, kalimat efektif tidak bertele-tele, jelas, dan padat agar dapat dipahami pembaca atau pendengar. Sementara itu, (Rahmawati, 2011) berpendapat bahwa kalimat efektif adalah kalimat yang dapat mengungkapkan gagasan secara tepat dan dapat dipahami oleh orang yang membacanya. Lebih rinci, Putrayasa \& Susana (2007) mengatakan bahwa kalimat yang baik harus memperhatikan tiga hal, yaitu (1) penggunaan bahasa Indonesia yang baik dan benar, (2) penggunaan bahasa Indonesia yang baku, dan (3) penggunaan ejaan yang disempurnakan.

Soedjito \& Saryono (2011) menyatakan bahwa kalimat efektif yaitu kalimat yang mengungkapkan gagasan yang dapat dipahami secara tepat dengan ciri-ciri lengkap, logis, serasi, padu, hemat, cermat, tidak rancu, dan bervariasi, serta kalimat yang efektif merupakan kalimat yang tidak memiliki subjek ganda. Kesepadanan dan keparalelan kalimat dilihat dari susunan kata yang runtut dan sesuai dengan fungsi formulasi sebuah kalimat. Oleh sebab itu, menulis kalimat efektif memerlukan keseimbangan antara pikiran dan struktur bahasa yang digunakan dengan kehematan untuk menghindari reduplikasi, pleonasme, hiponimi dan penjamakan, tidak ambigu, serta kalimat yang berisi kepaduan pernyataan. Dengan demikian, kalimat dikatakan kalimat efektif diperlukan unsur-unsur dalam pemakaian kata sehingga makna ide atau gagasan seseorang dapat diterima oleh pembaca. Unsur-unsur yang membangun sebuah kalimat adalah subjek, predikat, objek, pelengkap, dan keterangan atau sekurang- kurangnya memiliki subjek dan predikat. Hal tersebut merupakan unsur dari kalimat efektif supaya pembaca mudah memahami materi yang disampaikan penulis.

Dalam bahasa tulis, kalimat efektif sangat diperlukan, khususnya penggunaan ejaan. Bahasa tulis sangat tidak sempurna karena intonasi tidak dapat dinyatakan sebagaimana mestinya. Oleh sebab itu, turun naiknya suara tidak dapat digambarkan dalam bahasa tulis. Salah satu bahasa tulis adalah karya tulis ilmiah.

Penggunaan kalimat efektif sangat diperlukan dalam menyusun karya tulis ilmiah agar gagasan yang disampaikan penulis dapat dipahami pembaca. Susanti (2015) menyatakan bahwa karya 
tulis ilmiah membahas permasalahan keilmuan yang dituangkan ke dalam tulisan berupa gagasan ilmiah, kajian ilmiah, maupun hasil penelitian. Dengan demikian, diperlukan penguasaan unsur-unsur bahasa sampai dengan pengembangan kemampuan dalam melakukan tahap-tahap proses kreatif dalam menulis karya tulis ilmiah. Dalam menulis karya tulis ilmiah, harus diperhatikan tata bahasa dengan penulisan yang logis dan sistematis, sehingga menghasilkan tulisan yang runtut dan terpadu. Di samping itu, diperlukan kecermatan dan ketelitian serta tulisan yang sistematis sehingga hasil tulisannya dapat dimengerti pembaca saat menulis karya tulis ilmiah.

Karya tulis ilmiah terdiri atas makalah, proposal, laporan penelitian, skripsi, tesis, disertasi, dan proposal (Jauhari, 2010) Guru yang berkualitas memunyai kemampuan menulis karya tulis ilmiah dengan menggunakan kalimat efektif. Saat menulis karya tulis ilmiah, kalimat efektif merupakan salah satu kendala yang dialami guru. Hal tersebut dapat dibuktikan dengan beberapa guru menulis karya tulis ilmiah belum menggunakan kalimat efektif. Adapun kesulitan yang dihadapi oleh guru dalam menyusun kalimat efektif diantaranya (1) ketidaksepadanan struktur, (2) ketidakcermatan, (3) ketidakhematanan, (4) ketidakparalelan, (5) ketidaklogisan. Berdasarkan fenomena tersebut, PPM ini perlu dilaksanakan agar guru dapat menyusun karya tulis ilmiah dengan menggunakan kalimat efektif. Pemerintah melalui Kementerian Pendidikan Nasional seperti yang diamanatkan dalam UndangUndang Nomor 20 tahun 2003 tentang Sistem Pendidikan Nasional, Undang- Undang nomor 14 tahun 2005 tentang Guru dan Dosen, dan Peraturan Pemerintah Nomor 19 Tahun 2005 tentang Standar Nasional Pendidikan, akan memfasilitasi guru untuk dapat mengembangkan keprofesian secara berkelanjutan. Pengembangan keprofesian berkelanjutan adalah pengembangan kompetensi guru yang dilaksanakan sesuai dengan kebutuhan, bertahap, berkelanjutan untuk meningkatkan profesionalitasnya (Negara, 1991).

Salah satu jenis pengembangan keprofesian berkelanjutan adalah publikasi ilmiah berupa hasil penelitian atau gagasan ilmu bidang pendidikan formal. Karya tulis ilmiah guru dapat dipublikasikan dalam bentuk laporan hasil penelitian atau laporan/gagasan ilmiah yang ditulis berdasar pada pengalaman dan sesuai dengan tugas pokok serta fungsi guru.

Berdasarkan fenomena yang terjadi akhir- akhir ini adalah minimnya produktivitas guru dalam menulis karya tulis ilmiah karena adanya beberapa faktor penghambat dalam menulis. Salah satu faktor tersebut adalah menulis kalimat efektif. Hal tersebut yang melatarbelakangi program PPM ini dilaksanakan oleh tim Prodi PBI, Fakultas Ilmu Sosial dan Humaniora, Universitas PGRI Adi Buana Surabaya.

\section{METODE}

Kegiatan PPM ini dilaksanakan untuk mencari solusi kekurangpahaman guru dalam menulis kalimat efektif ketika menyusun karya tulis ilmiah, khususnya saat menulis penelitian tindakan kelas (PTK). Masalah kekurangpahaman guru terhadap kalimat efektif dalam penyusunan PTK dapat 
diatasi dengan memberikan pelatihan penulisan kalimat efektif pada PTK. Pelatihan dilaksanakan tanggal 24 Agustus 2020 oleh tim dosen dan mahasiswa Prodi Pendidikan Bahasa Indonesia, Fakultas Ilmu Sosial dan Humaniora, Universitas PGRI Adi Buana Surabaya daring. Hal tersebut dilaksanakan karena kondisi masih pandemi sehingga dengan beberapa pertimbangan diputuskan untuk tidak bertatap muka secara langsung. Metode pelaksanaan yang digunakan dalam kegiatan PPM ini terdiri atas beberapa tahap. Adapun tahapan tersebut dijelaskan sebagai berikut.

\section{Perencanaan}

Perencanaan pelatihan dilakukan dalam empat tahap. Adapun pemaparan masing-masing tahap seperti berikut. Tahap pertama yaitu persiapan. Kegiatan yang dilakukan adalah tim panitia PPM Prodi PBI berkoordinasi untuk melakukan observasi awal dan berkomunikasi dengan sekolah mitra (Kepala Sekolah UPT SMPN 10 Gresik) tentang kendala- kendala yang dialami guru saat menyusun karya tulis ilmiah. Kemudian, tim panitia melaksanakan rapat koordinasi untuk menentukan materi sesuai dengan tema dan pemateri. Setelah materi dan pemateri ditentukan, kegiatan berikutnya adalah mempersiapkan dokumen-dokumen pendukung, misalnya surat izin, surat tugas, surat permohonan, bedrop, presensi, dan sertifikat.

2. Pelaksanaan dan pelatihan

Kegiatan pada tahap ini adalah sosialisasi awal pelatihan dan pelaksanaan pelatihan. Tim bersosialisasi awal tentang kegiatan pelatihan dan melaksanakan kegiatan pelatihan yang telah disepakati bersama. Salah satu kesepakatan adalah kegiatan dilaksanakan secara daring atau virtual karena sedang pada masa pandemi. Metode daring mrupakan paparan, diskusi, dan latihan menulis kalimat efektif. Materi yang diberikan pada pelatihan ini adalah (1) masalah umum dalam penulisan karya tulis ilmiah, (2) karakteristik masalah intelektual dalam penulisan karya tulis ilmiah, dan (3) ciri-ciri kalimat efektif (materi pelatihan berupa power point). Walaupun menggunakan metode daring, perubahan kemampuan guru apabila dibandingkan antara sebelum dan setelah mengikuti latihan cukup berbeda.

3. Pendampingan dan evaluasi

Pada tahap ini, kegiatan yang dilakukan adalah tim pemateri melakukan kegiatan pendampingan bagi guru dalam pembuatan karya tulis ilmiah, khususnya menyusun penelitian tindakan kelas (PTK). Karya tulis berbentuk PTK dipilih guru karena pada umumnya guru mengalami kesulitan membuat kalimat efektif saat menyusun PTK. Setelah pendampingan selesai, tim PPM mengadakan evaluasi dengan memberikan angket keterlaksanaan program PPM Prodi PBI dan mereviu penulisan kalimat efektif pada PTK Guru UPT SMPN 10 Gresik. 


\section{Pembuatan Laporan}

Kegiatan yang dilakukan pada tahap ini adalah tim PPM melakukan koordinasi dengan subtema masing-masing untuk menyusun laporan akhir kegiatan PPM. Setelah laporan akhir selesai disusun, kegiatan berikutnya adalah membuet artikel untuk dipublikasikan.

Sasaran yang dituju pada kegiatan PPM ini ialah guru-guru SMPN 10 Gresik. Jumlah peserta pelatihan adalah tiga puluh orang.

\section{HASIL DAN PEMBAHASAN}

\section{Pelaksanaan Pelatihan}

Pelaksanaan pelatihan dilaksanakan Senin, 24 Agustus 2020. Kegiatan ini dilakukan dalam tiga tahap. Ketiga tahap tersebut dijelaskan seperti di bawah ini. Tahap pertama adalah pelaksanaan tes awal. Tes ini dilakukan dalam bentuk tes unjuk kerja, yakni semua peserta diminta untuk menuliskan kembali kalimat-kalimat pada PTK (bab I) yang pernah dibuat. Hal tersebut bertujuan mengetahui kemampuan awal peserta menggunakan kalimat efektif dalam menyusun PTK. Berdasarkan hasil pretes, dapat dideskripsikan kemampuan awal guru sebelum mengikuti kegiatan pelatihan. Dari keseluruhan peserta, guru yang memiliki kemampuan membuat kalimat efektif dengan kriteria kesepadanan struktur 15\%, kecermatan sebanyak 10\%, kehematan sebanyak $10 \%$, keparalelan sebanyak $20 \%$, dan kelogisan sebanyak $25 \%$.

Tahap kedua adalah tim melaksanakan pelatihan. Secara umum, materi pelatihan yang diberikan adalah penggunan kalimat efektif dalam penyusunan PTK.

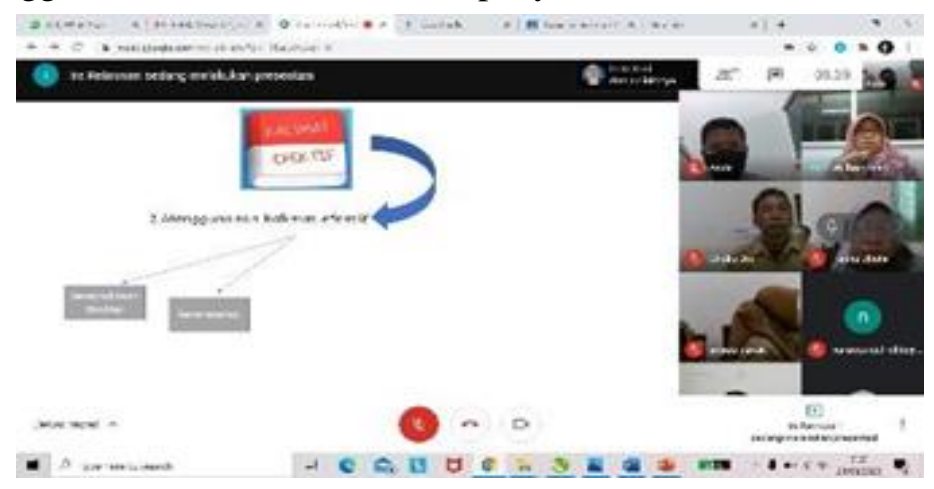

Gambar 1. Pemateri memaparkan penulisan kalimat efektif

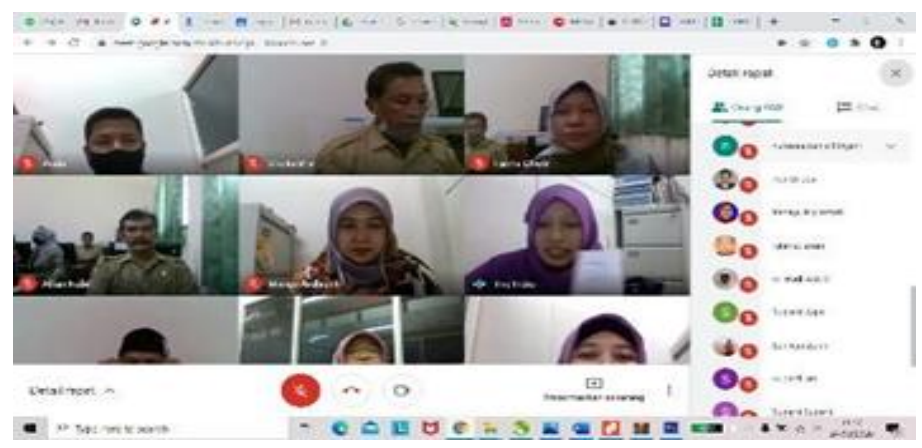


Gambar 2. Tim PPM dan para Guru UPT SMPN 10 Gresik

Tahap ketiga adalah tim melaksanakan tes akhir (postes) dalam bentuk unjuk kerja. Peserta diminta menyusun PTK (bab I) dengan menggunakan kalimat efektif. Berdasarkan hasil tes akhir, ditunjukkan ada peningkatan apabila dibandingkan dengan hasil tes awal. Setelah melalui latihan ini, kemampuan guru dalam membuat kalimat efektif meningkat, yakni kemampuan guru menulis kalimat dengan kriteria kesepadanan struktur sebesar 70\%, kecermatan 65\%, kehematan sebesar 80\%, keparalelan 70\%, dan kelogisan sebesar $75 \%$.

Peningkatan kemampuan menulis kalimat efektif pun cukup tinggi. Hal tersebut disebabkan oleh latar belakang profesi peserta yaitu sebagai guru. Bagi guru, menulis kalimat efektif bukan hal yang baru. Kesalahan guru saat menulis kalimat efektif lebih banyak disebakan oleh ketidakterpahaman ciri- ciri kalimat efektif. Selain itu, frekuensi menyusun PTK sebelum mengikuti pelatihan masih kurang. Oleh sebab itu, meskipun pelatihan ini menggunakan metode daring, perubahan yang terjadi setelah mengikuti pelatihan cukup signifikan.

Penentuan indikator pelatihan didasarkan pada teori dalam menulis kalimat efektif. Berdasarkan teori, kemampuan menulis kalimat efektif dapat diukur berdasarkan lima kriteria, yakni kesepadanan struktur kecermatan, kehematan, keparalelan, dan kelogisan. Sebenarnya, masih ada beberapa indikator yang dapat dijadikan sebagai kriteria kemampuan menulis kalimat efektif. Akan tetapi, kelima indikator tersebut sudah dapat dijadikan sebagai standar karena dapat mengukur kemampuan seseorang dalam kalimat efektif.

\section{KESIMPULAN}

Pelatihan menulis kalimat efektif pada PTK bagi Guru UPT SMPN 10 Gresik ini cukup berhasil. Hal ini terlihat dari hasil tes kemampuan peserta dalam menulis surat resmi, sebelum (pretest) dan setelah pelatihan (posttest). Berdasarkan hasil tes hasil tes awal, guru yang memiliki kemampuan menulis membuat kalimat efektif dengan kriteria kesepadanan struktur 15\%, kecermatan sebanyak 10\%, kehematan sebanyak $10 \%$, keparalelan sebanyak 20\%, dan kelogisan sebanyak $25 \%$.

Persentasi nilai dari masing-masing kriteria terebut meningkat setelah pelatihan dilaksanakan. Berdasarkan hasil tes akhir, kriteria kesepadanan struktur sebesar 70\%, kecermatan 65\%, kehematan sebesar $80 \%$, keparalelan $70 \%$, dan kelogisan sebesar $75 \%$.

Secara keseluruhan, kegiatan PPM oleh Prodi PBI berjalan dengan lancar meskipun sedikit terganggu karena sinyal kurang bagus. Guru UPT SMPN 10 Gresik cukup antusias dalam mengikuti pelatihan sejak awal dan akhir. Keantusiasan guru dibuktikan dengan banyak guru yang bertanya tentang materi yang diberikan dan kendala yang dialami dalam menulis kalimat efektif ketika sesi tanya jawab. Berdasarkan hasil kuesioner, kegiatan pelatihan dinilai efektif dengan melihat tingkat 
keterlaksanaan kegiatan PPM cukup tinggi dan peserta mengharapkan kegiatan lanjutan dalam menulis kalimat efektif.

\section{UCAPAN TERIMA KASIH}

Tim penulis mengucapkan terima kasih kepada Universitas PGRI Adi Buana Surabaya, khususnya Lembaga Penelitian, Pengembangan, dan Pengabdian kepada Masyarakat (LP3M) yang telah mendanai program pengabdian kepada masyarakat ini. Ucapan terima kasih juga diucapkan kepada UPT SMPN 10 Gresik, kepala sekolah dan guru-guru UPT SMPN 10 Gresik sebagai mitra yang telah mendukung pelaksanaan program PPM Prodi PBI ini.

\section{DAFTAR PUSTAKA}

Hs, W. (2012). Bahasa Indonesia Mata Kuliah Untuk Pengembangan Kepribadian di Perguruan Tinggi. Jakarta: Kompas Pustaka.

Jauhari, H. (2010). Panduan penulisan skripsi teori dan aplikasi. Bandung: Pustaka Setia.

Negara, S. (1991). Peraturan Pemerintah Republik Indonesia No. 72 tahun 1991 tentang PLB. Jakarta: Sekretariat Negara.

Putrayasa, I. B., \& Susana, A. (2007). Kalimat efektif:(diksi, struktur, dan logika). Refika Aditama.

Rahmawati, N. (2011). Bahasa Indonesia Keilmuan di Perguruan Tinggi. Bandung: Khalifa Insan Cendikia Pres.

Soedjito \& Saryono, D. (2011). Seri terampil menulis: kosakata bahasa Indonesia. Malang: Aditya Media Publishing.

Susanti, R. (2015). Kesalahan penggunaan eyd dalam karya ilmiah mahasiswa Politeknik Indonusa Surakarta. Jurnal IKON Prodi D3 Komunikasi Massa-Politeknik Indonusa Surakarta, 1(2), 3450. 